\section{High-Resolution Angioscopic Observation of Deep Vein Thrombosis After Catheter-Directed Venous Thrombolysis}

Atsutoshi Hatada, MD, PhD; Yusaku Takagaki, MD, PhD; Shuji Yamamoto, MD, PhD; Yoshitaka Okamura, MD, PhD; Yoshiharu Nishimura, MD, PhD

V enous angioscopy has not been reported. Here we describe successfully observing veins by highresolution angioscopy (Zemporshe; Taisho Biomed Instruments, Osaka, Japan) in the week after catheterdirected thrombolytic treatment (CDT).

A 67-year-old woman presented with right leg swelling. Contrast-enhanced computed tomography showed an occlusion of the right iliofemoropopliteal vein by thrombus. She was treated with CDT, followed by anticoagulation and thrombolytic therapy. Venography and angioscopy (Figure) at 1 week after CDT showed a fibrous strand of thrombus in the femoropopliteal vein and absence of thrombi in the iliofemoral vein.

Obstruction of a vein by a thrombus damages the vessel wall by the inflammatory process. ${ }^{1}$ The longer the thrombus is in contact with the wall, the greater the damage, ${ }^{2}$ leading to post-thrombotic syndrome (PTS). Early elimination of the thrombus may preserve valvular function and prevent fibrosis, a sequela of chronic thrombus. ${ }^{3}$ As in this case, high-resolution angioscopy after venous thromboembolism could predict the occurrence of PTS.

\section{Disclosure}

The authors declare that there are no conflicts of interest.

\section{References}

1. Henke PK, Varma MR, Moaveni DK, Dewyer NA, Moore AJ,

Received May 15, 2020; revised manuscript received June 23, 2020; accepted June 29, 2020; J-STAGE Advance Publication released online August 25, 2020 Time for primary review: 17 days

Department of Cardiovascular Surgery, Wakayama Saiseikai Hospital, Wakayama (A.H., Y.T., S.Y.); Department of Thoracic and Cardiovascular Surgery, Wakayama Medical University, Wakayama (Y.O., Y.N.), Japan

Mailing address: Atsutoshi Hatada, $\mathrm{MD}, \mathrm{PhD}$, Nishinomiya Watanabe Cardiovascular Center, 3-25 Ikeda-cho, Nishinomiya 662-0911, Japan. E-mail: hatada@n-watanabe-hosp.jp

All rights are reserved to the Japanese Circulation Society. For permissions, please e-mail: cj@j-circ.or.jp ISSN-1346-9843
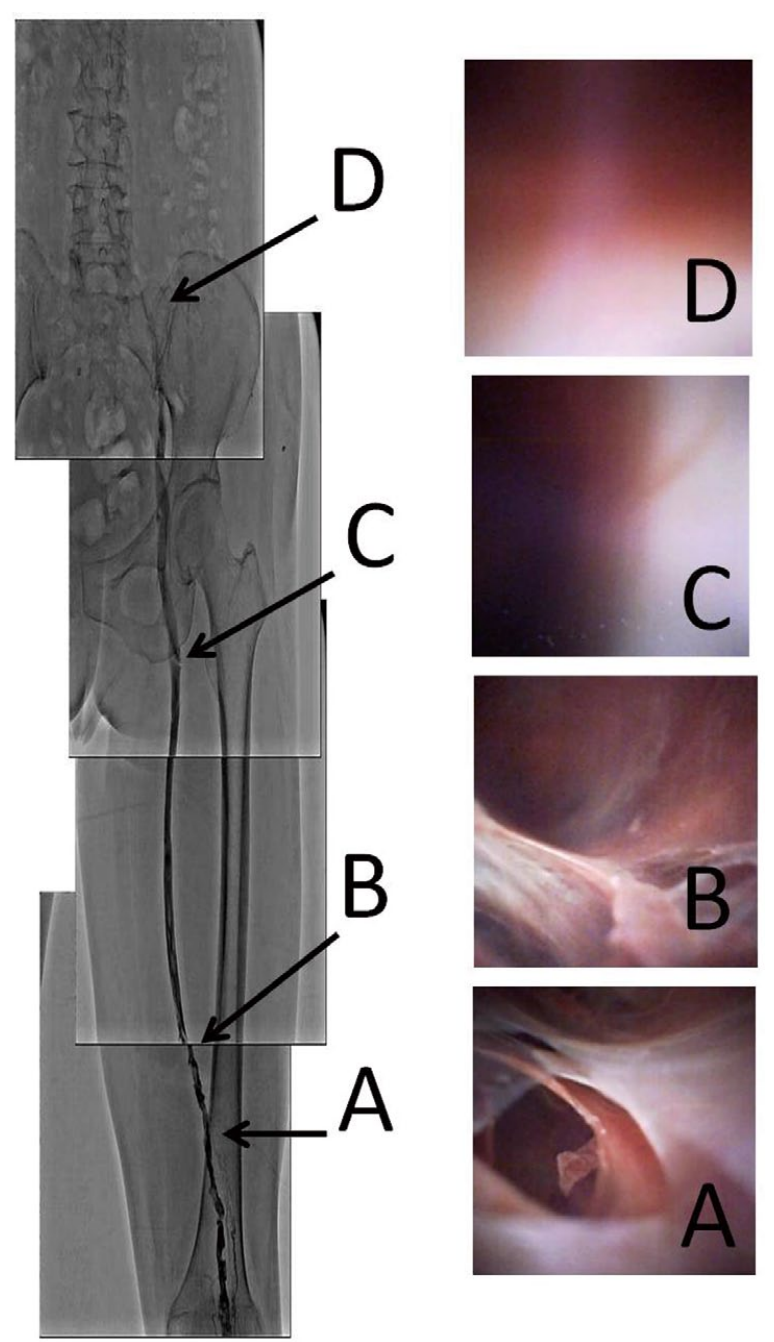

Figure. (Left) Venography showing stenosis of the right femoral vein. (A,B) Angioscopy showing the fibrous strand. (C,D) Angioscopy showing no thrombus.

Lynch EM, et al. Fibrotic injury after experimental deep vein thrombosis is determined by the mechanism of thrombogenesis. Thromb Haemost 2007; 98: 1045-1055.

2. Henke PK, Comerota AJ. An update on etiology, prevention, and therapy of postthrombotic syndrome. J Vasc Surg 2011; 53: $500-509$.

3. Meissner MH, Manzo RA, Bergelin, RO, Markel A, Strandness DE Jr. Deep venous insufficiency: The relationship between lysis and subsequent reflux. J Vasc Surg 1993; 18: 596-605; discussion 606-608. 